\section{SERPENTS AT DINNER}

BY C. FEW SEISS.

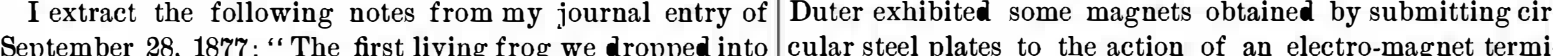
our snake house to-day had scarcely touched the floor into cular steel plates to the action of an electro-magnet termi-

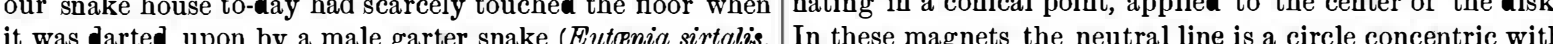
Linn.) and seized by the knee of the right hind limb. Nearly the disk. In order to study the magnetism, M. Duter uses at the a

endeavored to drag it from

the jaws of the other snake.

The confusion caused by this

struggle for a dinner aroused a large female eutonia, which hastened to the scene, and immediately seized the frog by the foot of the same le which was in the jaws of the first snake. The commotio which followed was, for few minutes, great; the writhing of the serpents while they tugged at the frog, and the vehement struggling and kicking of the frog itself, caused the pebbles to fly and mitle about rathle about quite violently. But the female autania be gan immediately to swallow the foot and leg of the frog she had seized, and continue to do so until her jaws came in contact with those of the male eutcenia. The latter wa unable to make any progres in swallowing, as he had grasped the frog at the knee, and was trying to force it to flex the leg, ,or draw the tibia up toward the femur, so that he might swallow them together, or side by side. The

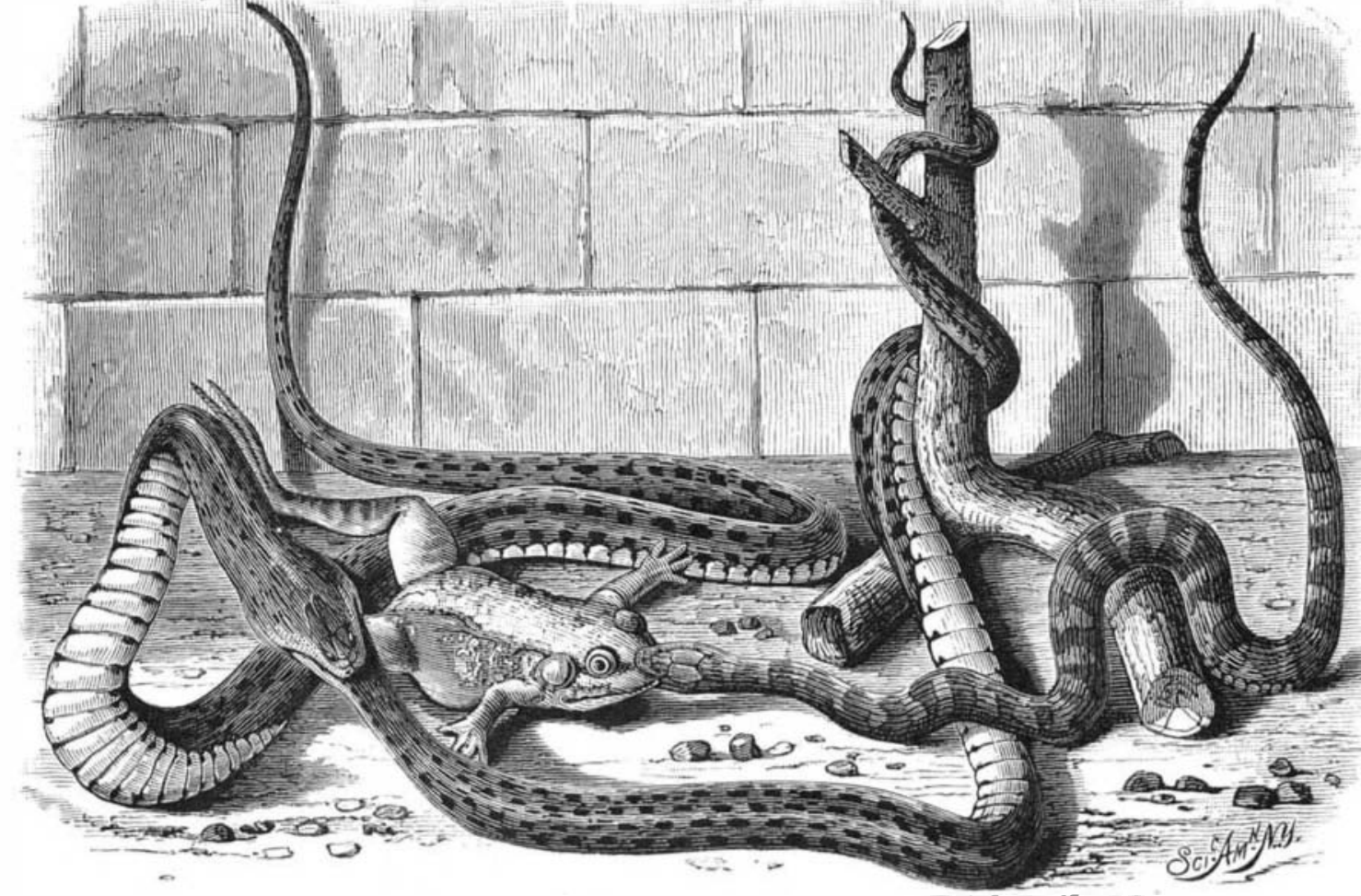

SERPENTS AT DINNER her left cheek. Great prostration occurred and increased until admission. Sloughing rapidly took place, the cheek bone became perforated, and the inferior maxillary bone necrosed. Copious hemorrhage ensued on the thire day after admission, and on the same day broncho-pneumonia set in. The childdie eight days after admission. The post mortem examination revealed very extensive necrosis of the tissues surrounding the left cheek and left side of the tongue and pecrosis of both superior and inferior maxille. The bas of both lungs were consolidated.

On the third day after ad mission the first micros copical examination of the blood during life was made. The white elements were in excess, and many existed in fragmentary condition. amined by a high power, a large number of small, highly refractile bodies, resembling minute colorless crystals, were seen in active movement. Reagents acted upon

female apparently took no notice of the jaws she had tachment is estimated by the weight of water caused to them variously: weak solutions of carbolic acid and of quithus met on her road to dinner, but swallowed them, the escape from the cylindrical vase containing the areometer nine arrested their movements, weak solutions of potash remainder of the head, and the neck also! This unlooked before contact is broken. The precise instant of contact and of sulphuric acid stimulated them. The number of 作 ivory paper folder and worked it carefully under her upper Duter has thus demonstrated experimentally that the quan- hemorrhage and fall of temperature they were greatly rejaw, thus unhooking the teeth from the other snake, and so tities of opposite magnetisms ( $\mathrm{N}$ and $\mathrm{S}$ ) were equal in two duced in number; again, when the temperature had risen ending the swallowing operation. A moment later, the opposite parts of the same plate. His present investigations to $103^{\circ}$ Fah., they were in great abundance. When numermale drew his head from its distasteful position, and al- now tend to the determination of the conditions existing in ous, they tended to form groups resembling zoögloa. In size though his neck was much lacerated and was bleeding pro- plates of different diameter, and it bas thus far been found they were one twentieth part of an ordinary red blood corfusely, he still retained his hold on the rog, and instantly began swallowing it, which he finished in two minutes, we having forced the water snake to unhook its teeth from the frog's snout. The second frog we put in was soon captured and devoured by the disappointed auto devoured by the disapponted oulonia. We then gave the water snat have been a frog, but was -a tadpole." an instance of cannibalism among any species of American serpents known to me. We have no ophiophagi or snake-eatin snakes in this country. The partia swallowing of the eutrenia mentione was, I think, unintentional on the part of the swallower, and of course on that of the swallowed.

\section{GATHERING TODDY.}

The borassus tribe (Borassinece) of palms consists of trees with fan-shape or pinnate leaves, a wondy fibrous or net-like spathe, and the fruit a drupe The principal genus is the magnificen Palmyra palm, represented in our engraving. Of this the most important products are palm wine (toddy) and sugar. When the flower spike and its appearance the operator ascends the its appearance the operator ascends the tree by the aid of a vine or rope passed loosely around his owa body and the trunk. He ties the spathe securely so that it cannot expand, and beats the base of the spike with a short stick. This beating, which is supposed to determine a flow of sap toward the wounded part, is repeated for severa successive mornings, when a thin slice is removed from the end of the spathe. A about the eighth day the sap begins to flow at the rate of two pints daily, and continues to exude for four or five months, a slice of the spathe being removed every morning. This juice readily ferments, and is then palm wine or toddy. When distilled it yields the spirit known as arrack, or if allowed to pass to acetous fermentation it become vinegar.

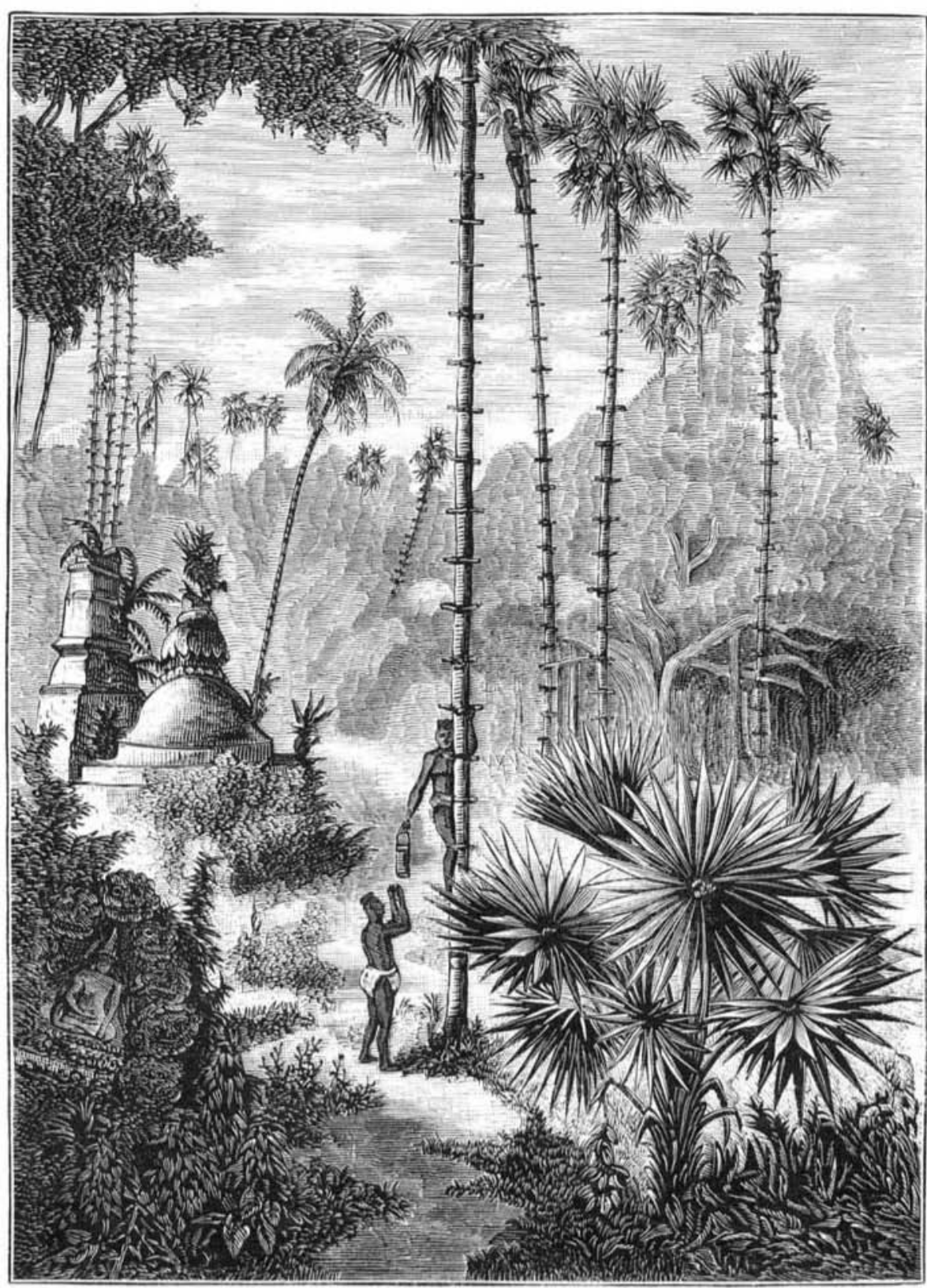

THE PALMYRA PALM. puscle. Shortly before death ordinary bacteria were observed in addition to the translucent bodies. These latter bodies were found in the urine examined immediately after being voided, and in large number in the fæces. The discharges from the wound also manifested them in abundance.

Investigations respecting the infective character of the blood and secretions were commenced on the second day after the child's death, the fluids preserved for inoculation having been kept in sealed capillary tubes. A healtby mouse inoculated with blood from the right auricle died on the day following, and on examination showed evidence of peritonitis, the exudations conting bodies exactly rese num bodies exactly rese ent in the blood of the child. A guinea pig treated in the same way died five days after the operation; its blood contained a vast number of the special translucent bodies. Inoculation of the fluids from the seat of the noma was practice upon a mouse and a cat. Both animals died, and there was a complete absence of the motile translucent bodies from their blood.

It would appear, therefore, that while inoculation of the fluids derived from the diseased tissue produced peritonitis without discoverable alteration of the blood, inoculation of the diseased blood induced septicæmia, with the manifestation of the characteristic motile particles observed in the original disease. The organisms resembled amœbæ rather than bacteria.

\section{Bacteria.}

Dr. Arthur Downes and Mr. T. P. Blunt presented to the Royal Society the result of most interesting observations on the effect of light upon bacteria and other organisms. The experiments were carried out in great detail, and their record is too lengthy to be given in full. The deductions to be drawn may be summed up as follows: 